\title{
Invited commentary on ... . Ethnic variations in pathways into early intervention services for psychosis ${ }^{\dagger}$
}

Richard Warner

\author{
Summary \\ Advocates of early intervention in psychosis choose to \\ treat the association between long duration of untreated \\ psychosis (DUP) and poor outcome as evidence that \\ reducing DUP will improve outcomes. I question this \\ view and argue that DUP does not predict outcome
}

but rather that mode of onset of psychosis predicts DUP and outcome.

\section{Declaration of interest}

None.
Horatio Nelson at the Battle of Copenhagen, then a vice-admiral, is famously reputed to have responded to a signal from the admiral's flagship suggesting that he withdraw from the fight, by holding a telescope to his blind eye and declaring, 'I really don't see the signal. He went on to win the battle. Ghali and colleagues ${ }^{1}$ are guilty of the same sort of deliberate blindness in pursuit of a noble purpose, but, in the process, they do harm to their scientific credibility.

\section{The error}

In the first paragraph of their article, ${ }^{1}$ the authors assert, 'A central tenet of the early intervention services model is early detection of psychosis and initiation of pharmacotherapy. This is supported by a substantial body of evidence confirming an association between duration of untreated psychosis (DUP) and poorer outcome'. Let us examine this premise, which is, truly, a central tenet of the early intervention service model. So much so, that to abandon it, may be to lose the battle. Thus, the deliberate blindness to contrary evidence.

As I pointed out in a previous article in this journal, ${ }^{2}$ a problem with the assumption that prolonged DUP causes poor outcome due to a delay in beginning pharmacotherapy is the observation that the benefits of early intervention in psychosis were observed at least 200 years ago, long before the advent of antipsychotic medication. At that time, the evidence for the claim was this same association of DUP with outcome. 'Throughout the nineteenth century', writes Scull, ${ }^{3}$ 'it was an article of faith among those who dealt with lunatics that the deranged were more easily restored in the early stages of the disorder' (p. 111). In 1828, for example, a private madhouse proprietor reported that 'of sixty-nine cases admitted within three months of the first attack, sixty were cured; of seventy cases admitted five months after the onset of the attack, however, only twelve were cured' (p. 203). ${ }^{4}$ The British Metropolitan Commissioners of Lunacy cited tables 'exhibiting the large proportion of cures effected in cases where patients are admitted within three months of their attacks' (p. 112) ${ }^{3}$ and the Westminster Review similarly pointed to 'the very great probability of cure in the early stages of insanity' (p. 112). These observations bolstered support for the two acts of 1845 The Lunacy Act and The County Asylums Act - and the subsequent construction of a network of, sometimes massive, county asylums. It does not take 20:20 hindsight to see past the self-promotion of the madhouse proprietors and the optimism

†See pp. 277-283, and editorial pp. 249-250, this issue. of the parliamentarians to recognise that the observed association between DUP and outcome in psychosis was not due to any specific intervention but to the simple fact that samples of patients admitted early to treatment are more likely to have brief, good-prognosis psychosis, whereas those with long DUP, by definition, exclude such cases. (We should note that first episodes of schizophreniform disorder progress to early remission in $25-50 \%$ of cases. ${ }^{5-7}$ ) What was true in the 1800 s continues to be true now and it should not take superior scientific acumen to recognise this fact; it merely requires taking off the blinkers.

\section{The consequences}

How does Ghali et al's focus on prolonged DUP as a cause of poor outcome affect their conclusions? They observe that DUP was more prolonged in White British patients than in Black patients and that Black patients were more likely to enter treatment via emergency medical treatment or through contact with the criminal justice system. The conclusion that many readers would draw from these findings is that White patients with insidious-onset psychosis are more likely to eventually enter treatment and, thus, extend the average DUP; whereas Black patients present more often with acute-onset, agitated psychosis, and those with insidious onset are less likely to enter treatment. The implication from this reading of the data would be that we need to enhance routes to treatment for Black patients with insidious onset of illness. With their focus on DUP, however, the authors draw a contrary conclusion, namely 'for White British patients, reducing delays currently encountered via primary care is central. ${ }^{1}$ Given their own observation that early intervention services have not 'had a substantial effect either on DUP or on routes into services, ${ }^{1}$ this may not prove to be a productive approach. For Black patients, the authors conclude that the emphasis must be on 'reducing coercive routes to services', rather than on increasing referral of Black patients with insidious-onset psychosis to treatment. Their suggestion that what is needed is 'some form of public education and direct access to services, ${ }^{1}$ although practically very difficult, is appropriate to both approaches. However, there is no suggestion in their article that we should view an increase in DUP for Black patients as a measure of success, which would be true if we were aiming to detect and treat more Black patients with insidious onset. This goal would not fit well with the view in the early intervention service field that shorter DUP equals better outcome. 
The authors struggle with their interpretation of the data on Black patients since they are obliged to conclude that the differences between DUP in White and Black patients may be due to 'ethnic variations in the clinical presentation of psychotic illness.' In fact, they go so far as to report that 'mode of psychosis onset, as a variable, tends to plague studies exploring DUP as its insidious form has been shown to be associated with prolonged DUP.' ${ }^{1}$ In other words, they admit that acute conditions present with a briefer DUP, which is the reverse of the conclusion they draw in their opening paragraph.

It is time that early intervention service advocates recognise that DUP does not predict outcome - mode of onset predicts DUP and outcome. If Ghali and his co-authors were to do so, their recommendations might well be different. Based on the data in this paper, one could ask, if Black patients are presenting substantially more often with acute-onset (and potentially goodprognosis) psychoses, is this, in part, because of a biological factor such as marijuana misuse and should we allow such patients some days free of medication after admission to see whether the illness goes into remission? The early intervention approach would point us in the opposite direction, but rapid intervention with pharmaceuticals runs the danger of muddying the diagnosis and worsening outcome from illness.
Richard Warner, MB, DPM, Colorado Recovery, 2818 13th Street, Boulder, CO 80304, USA. Email: rwarner@coloradorecovery.com

First received 11 Aug 2012, accepted 4 Sep 2012

\section{References}

1 Ghali S, Fisher HL, Joyce J, Major B, Hobbs L, Soni S, et al. Ethnic variations in pathways into early intervention services for psychosis. Br J Psychiatry 2013; 202: 277-83.

2 Warner R. Problems with early and very early intervention in psychosis. Br J Psychiatry 2005; 187 (suppl 48): s104-7.

3 Scull AT. Museums of Madness: The Social Organization of Insanity in Nineteenth Century England. St Martin's Press, 1979.

4 Parry-Jones WL. The Trade in Lunacy: A Study of Private Madhouses in England in the Eighteenth and Nineteenth Centuries. Routledge and Kegan Paul, 1972.

5 World Health Organization. Schizophrenia: An International Follow-up Study. Wiley, 1979.

6 Ciompi L. Catamnestic long-term study on the course of life and aging of schizophrenics. Schizophr Bull 1980; 6: 606-18.

7 Warner R. Recovery from Schizophrenia: Psychiatry and Political Economy (3rd edn). Brunner-Routledge, 2004.

\section{Speed limit!}

\section{Shabbir Amanullah}

Children often come out with the most interesting and often unique interpretation of their environment and interactions with others. Some are in reaction to a specific situation whereas others are often carefully thought of .... albeit in the child's own unique way.

While house-hunting in San Jose with my 4-year-old niece, my sister was driving through a rather busy neighborhood that had clearly posted speed limit signs. Having come off the motorway, the drop in speed was sudden and Zaara, who was up until that time watching the trees and cars go by her window, looked at her mum intently. Noticing Zaara's intense stare through the rear view mirror, my sister asked 'Is everything OK?'. Zaara seemed rather cross and didn't reply the first time round. 'Is everything OK, Zaara?', my sister asked a second time. In a slow deliberate tone, Zaara said: 'Why did you slow down? Go faster'. 'We can't', my sister explained, 'There are speed limits in different areas and we have to follow them'. There was no further discussion and through tours of different houses Zaara seemed busy with her toys and looking around the places they visited.

On returning home, she seemed tired and lost in her thoughts. While slowly chewing on her first spoonful of food, my sister came by with the second spoonful. Zaara was still on her first spoonful and turned her head away. 'Come on Zaara, you have to finish up and go to bed', said my sister. Slowly turning her head to face her mum, Zaara replied in a firm tone: 'I cannot do that mum, there are speed limits!' 